\title{
Progress on Polarized Target Materials with Pure Carbon Background*
}

\author{
D. A. Hill \\ Argonne National Laboratory, Argonne, IL 60499 \\ D. G. Crabb \\ University of Virginia, Charlottesville, VA 22901 \\ M. Krumpolc \\ University of Illinois at Chicago, Chicago, IL 60680
}

ANL-HEP-TR--93-15

DE93 011759

March 24, 1993

\section{Introduction}

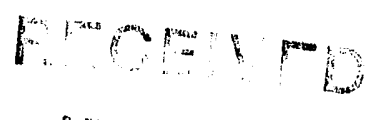

\section{Anil is 1003}

(i)

A previous note [1] reviewed methods for the paramagnetic doping of materials for spin-polarized solid targets and some of the history of attempts to apply those methods to hydrocarbons. Since the earlier work on hydrocarbons had yielded, at best, rather mediocre results, that note also speculated on some ways to extend and, possibly, to improve upon the earlier work. The sharpest focus was on the light (number of carbons less than six) alkanes, since these are the hydrocarbons that have the highest hydrogen contents $(\gtrsim 17 \mathrm{wt} \%)$ and therefore require the least degree of polarization to be interesting. This present note summarizes the subsequent work done, to date, exploring some of the issues related to the chemical doping method. The main areas of progress have been in the literature search, experimental results on glass formation by alkanes, and a polarizing test of a "prototype" hydrocarbon.

\section{Literature search}

A search for relevant napers on alkane properties was performed on the STN International, CAS Onlin database. This uncovered a few items of moderate interest, for example, some papers [2,3] containing information on glass transition temperatures and densities of some 5-, 6-, and 7-carbon alkanes. The major find was a rather obscure Russian paper [4] describing an experimental determination of the liquid-solid phase diagram of the binary system isobutane/n-butane. Experimentally, the eutectic occurs at $66.5 \mathrm{~mol} \%$ isobutane, and the eutectic melting temperature is $104.95 \pm 0.05 \mathrm{~K}$. These compare rather closely with the $68.4-\mathrm{mol} \%$ and $T_{e}=105.6-\mathrm{K}$ estimates of Ref. [1]. This suggests that the other estimates in [1], which are based on an assumption of ideal mixtures, may be fairly reliable.

"Work supported in part by the U. S. Department of Energy, Division of High Energy Physics, Contract No. W-31-109-ENG-38.

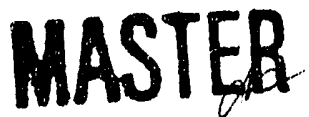

DISTRIBUTION OF THIS DOCUMENT IS UNLIMITES
The submitted manuscript has been authored by contrector of the U. S. Government under contrect No. W-31-109ENG-38. Accordingly, the U.S. Government retsins a nonexclusive, royalty-free license to publiah or reproduce the published form of this contribution, or allow others to do $\infty$, for Contribution, or allow others 
The search did not produce any papers on phase diagrams of alkane mixtures with $n_{\mathrm{C}}<4$, nor any substantial new information about glass formation by alkane mixtures.

\section{Experimental investigation of glass formation}

Benchtop microcalorimetry and visual observations at temperatures down to $77 \mathrm{~K}$, at Argonne, have been used to settle some of the questions raised in [1] about the glass-forming potential of alkanes with $n_{\mathrm{C}}$ as small as four.

\subsection{Materials}

The following liquids were obtained from Aldrich Chemical, rated at $99 \%$ purity: n-pentane, isopentane (2-methylbutane), 2-methylpentane, 3-methylpentane, and 3-methylhexane. After receipt, these liquids were kept over $4 \mathrm{~A}$ molecular sieve in order to minimize subsequent water contamination. Cylinders of $n$-butane and isobutane (2-methylpropane) were obtained from Matheson Gas, rated at $99.5 \%$. Neopentane (2,2-dimethylpropane) was not purchased, since it is rather expensive. In what follows, these substances are referred to by the following acronyms: $n$ butane (BU), isobutane (IB), n-pentane (PE), isopentane (IP), 2-methylpentane (2MP), 3-methylpentane (3MP), and 3-methylhexane (3MH).

\subsection{Tests of the pure materials}

As expected from prior experience [1] and information in the literature [2], the following pure materials proved to be easy glass-formers: IP, 2MP, 3MP, and $3 \mathrm{MH}$. That is, they consistently form glasses when drops are placed on the surface of $\mathrm{LN}_{2}$ or are placed in the microcalorimeter cup and quenched in $\mathrm{LN}_{2}$. At $77 \mathrm{~K}, \mathrm{IP}$ is a "soft" glass, with a viscosity similar to that of heavy molasses. (Technically, it is just a supercooled liquid at $77 \mathrm{~K}$, since this is above its glass transition temperature, $\approx 65 \mathrm{~K}$.) The other three form beads that are reasonably "hard" glasses at $77 \mathrm{~K}$, that is, they shatter when squeezed with cold forceps, and do not tend to stick to each other or to surfaces at $77 \mathrm{~K}$.

When held at $77 \mathrm{~K}$, the IP "beads" become visibly cloudy within $20 \mathrm{~min}$, which is probably due to slow bulk devitrification (crystallization) at this temperature. In the scanning calorimeter, IP devitrifies rapidly at $\approx 88 \mathrm{~K}$ during an upward temperature scan, and then shows the expected crystalline melting point at $\approx 113 \mathrm{~K}$.

The $2 \mathrm{MP}, 3 \mathrm{MP}$, and $3 \mathrm{MH}$ are all very reluctant to crystallize at any temperature, on any short time scale. However, when stored at $77 \mathrm{~K}$ for sufficiently long periods, they all exhibit some changes: 


\section{DISCLAIMER}

This report was prepared as an account of work sponsored by an agency of the United States Governrnent. Neither the United States Government nor any agency thereof, nor any of their employees, makes any warranty, express or implied, or assumes any legal liability or responsibility for the accuracy, completeness, or usefulness of any information, apparatus, product, or process disclosed, or represents that its use would not infringe privately owned rights. Reference herein to any specific commercial product, process, or service by trade name, trademark, manufacturer, or otherwise does not necessarily constitute or imply its endorsement, recommendation, or favoring by the United States Government or any agency thereof. The views and opinions of authors expressed herein do not necessarily state or reflect those of the United States Government or any agency thereof. 
- $3 M F$. When stored at $77 \mathrm{~K}$, this material appeared to undergo heterogeneous crystallization during the first week of storage. At this point, about $1 / 3$ of the beads had crystallized, and the remainder were still glassy (hence, heterogeneous). Additional "aging" at $77 \mathrm{~K}$ for up to two months produced little further change. When deliberately broken under $\mathrm{LN}_{2}$, the crystallized beads appeared to be polycrystalline (non-transparent) throughout the bead. The "glassy" beads slowly, over a period of weeks, took on a visible cloudy appearance, but this was evidently some change limited to the surfaces of the beads, since, when broken under $\mathrm{LN}_{2}$, the interior parts of these beads appeared glassy. Calorimeter scans of the crystallized beads produced only a strong crystalline melting feature at $109 \mathrm{~K}$. Scans of the "glassy" beads produced only a very weak melting feature at this same temperature, confirming their (largely) non-crystalline character.

- 2MP. Long-term storage at $77 \mathrm{~K}$ did not produce bulk crystallization in any of the 2MP beads. As in the case of the 3MP "glassy" beads, all of the 2MP beads took on a cloudy appearance over time, but this happened more rapidly than for the 3MP, within a few days. When broken under $\mathrm{LN}_{2}$, the bead interiors appeared glassy. Calorimeter scans seemed to show some subtle evolution during the first few days of "aging," but even after two months, the beads retained a glass transition feature near $82 \mathrm{~K}$, a broad devitrification feature near $112 \mathrm{~K}$, and then the expected crystalline melting feature at $\approx 119 \mathrm{~K}$.

- $3 M H$. This material behaved similarly to $2 \mathrm{MP}$, with the following differences in detail: The "cloudy" bead surfaces appeared rather abruptly during the third week of storage. Calorimeter scans produced only a glass transition feature near $92 \mathrm{~K}$, with no trace of either devitrification or crystalline melting at higher temperatures.

As expected from limited prior experience and hints in the literature [5], and consistent with the suppositions in Sec. 3.2 of [1], the following pure materials are not easy glass-formers: $\mathrm{BU}, \mathrm{IB}$, and $\mathrm{PE}$. When liquid drops are placed on the surface of $\mathrm{LN}_{2}$, they rapidly form white, opaque, polycrystalline solids. When placed in the calorimeter cup, quenched in $\mathrm{LN}_{2}$, and scanned upward in temperature, no glass transition or devitrification features are produced, only crystalline melting features are produced at the expected melting points. In the case of $\mathrm{BU}$, an endothermic feature near $108 \mathrm{~K}$ is also produced, which is evidently to be identified with the allotropic (solid-solid) crystalline phase transition described in [4].

\subsection{Tests of mixtures}

The news on alkane mixtures is very good: Every "new" eutectic mixture tried so far has proven to be an easy glass-former. This includes binary mixtures in which 
only one, or neither, pure component is a glass-former.

The following mixtures were examined:

- $2 M P / P E$. By the methods in [1], the eutectic is estimated to be at $15.5 \mathrm{wt} \%$ PE. Beads of this composition form a fairly "hard" glass at $77 \mathrm{~K}$. Storage for a couple of weeks produces surface cloudiness similar to the pure 2MP glass.

- IP/PE. The eutectic mixture was estimated in [1] to be at $12.3 \mathrm{~mol} \% \mathrm{PE}$. Calorimetric examination suggests that the actual eutectic is near $14 \mathrm{~mol} \%$ PE. All mixtures examined up to $25 \mathrm{~mol} \% \mathrm{PE}$ (the highest admixture tried) appeared to be easy glass-formers. These glasses are not "hard" at $77 \mathrm{~K}$; they are somewhat "sticky," having the consistency of glue that has not quite "set."

- $B U / P E$. Neither pure component is a glass-former. A mixture containing 31.9 mol\% PE (estimated eutectic according to [1]) forms a "soft" glass at $77 \mathrm{~K}$ (viscosity about like molasses), which devitrifies in $\approx 10 \mathrm{~min}$.

- IB/BU. Again, neither component is a glass-former. As mentioned in Sec. 2, the experimental eutectic point is at $33.5 \mathrm{~mol} \% \mathrm{BU}$ [4]. Beads of this composition form a very "soft" glass (viscosity about like pancake syrup), which devitrifies in $\approx 5 \mathrm{~min}$ at $77 \mathrm{~K}$. In the scanning calorimeter, rapid devitrification occurs at $\approx 86 \mathrm{~K}$, followed by the expected crystalline eutectic melting point at $\approx 105 \mathrm{~K}$.

To date, this IB/BU mixture of two 4-carbon alkanes is the most hydrogen-rich $(17.3 \mathrm{wt} \% \mathrm{H})$ mixture that we have examined.

\subsection{Solubility of DTBN}

Although the upper limit of solubility has not been established in any particular case, it was observed that di-tert-butylnitroxyl (DTBN) is soluble in all of the above materials to the extent necessary for DNP. In particular, it was soluble in the liquid phase of the IB/BU mixture that was prepared at a temperature of $230 \mathrm{~K}$. Most of the other solubility checks were done at or near room temperature.

\section{Polarizing test}

It was noted in [1] that any alkane glass-formers having the highest possible hydrogen content would have glass-transition temperatures well below $77 \mathrm{~K}$, and that they would be impossible to prepare and manipulate with the conventional $\mathrm{LN}_{2}$-based handling techniques. The results of some of the explorations described above underscore that conclusion. It was therefore suggested that, before investing 
effort in working out lower-temperature techniques, one should test the prospects for DNP in one of the less hydrogen-rich hydrocarbons with $T_{g}>77 \mathrm{~K}$. Specifically, either 2- or 3-methylpentane was suggested as such a "prototype."

The apparatus at the $U$. of Virginia was available to run such a test, if the samples could be prepared at Argonne and shipped there.

\subsection{Choice of material}

Eventually, a eutectic mixture of 2- and 3-methylpentane (3MP/2MP) was settled on for the test. Such a mixture seems to form a glass that is more stable than those of either individual component. For example, after one month of storage at $77 \mathrm{~K}$, none of the 3MP/2MP beads crystallize (compare to 3MP, above) and they take three weeks or more to develop a visible surface cloudiness (compare to $2 \mathrm{MP}$, above). Calorimeter scans produce only a glass transition feature near $81 \mathrm{~K}$.

Since the 3MP/2MP mixtures are very reluctant to crystallize on any human time scale, the eutectic point could not be established experimentally, so it was estimated assuming an ideal mixture as in Ref. 19 of [1]. Furthermore, we were unable to find a value for the heat of fusion for $3 \mathrm{MP}$, so we used a plausible estimate: $H R^{-1} \approx 900 \mathrm{~K}$. The resulting estimated eutectic is at $37.1 \mathrm{wt} \% 2 \mathrm{MP}$ and $T_{e}=103.2 \mathrm{~K}$. This was the composition used for the polarizing test. This material has a hydrogen content of $16.37 \mathrm{wt} \%$.

\subsection{Dopant}

The DTBN that is sold by Aldrich Chemical these days is rated as only technical grade $(90 \%)$. Therefore, $1 \mathrm{~g}$ of the as-received material was further purified by molecular distillation, resulting in $0.6 \mathrm{~g}$ of DTBN with an estimated purity of $\geq 97 \%$. This was used to dope the test samples.

\subsection{Preparation of test beads}

First, a $14-\mathrm{g}$ batch of $3 \mathrm{MP} / 2 \mathrm{MP}$ was prepared, consisting of $8.81 \mathrm{~g} 3 \mathrm{MP}$ plus $5.19 \mathrm{~g} 2 \mathrm{MP}$, corresponding to the estimated eutectic mix, above. This was kept over $4 \mathrm{~A}$ sieve in a bottle at room temperature, and all of the samples were prepared from this same batch. In order to deoxygenate the material, the vapor space of the bottle was purged with dry $\mathrm{N}_{2}$, and the bottle was shaken for about 30 seconds, on the day that the batch was prepared. This procedure was repeated three days later, and again, after a further three days, on the morning of the day that the samples were prepared. Additionally, the vapor space was purged after each subsequent opening of the bottle for withdrawal of sample material. This deoxygenation method was chosen in consideration of the relatively high vapor pressure of the components of 
the mixture, the relatively small amount of material involved, and as a matter of convenience. The efficacy of this method is not known.

A total of four samples were prepared, differing only in the concentration of DTBN: $4 \times 10^{19}, 3 \times 10^{19}, 2 \times 10^{19}$ spins $/ \mathrm{cm}^{3}$, and an undoped sample. The liquid phase was mixed at room temperature in an open test tube. (This necessarily entailed a brief, $\approx 2 \mathrm{~min}$, exposure to room air.) Then the mixture was beaded in a $\mathrm{LN}_{2}$ bath, electrostatically, using a needle pressurized with dry $\mathrm{N}_{2}$ and cooled to around $215 \mathrm{~K}$. (It was found that the beading process was much more controllable at a reduced temperature, probably because of the relatively high vapor pressure of the liquid at room temperature.) The diameter of the beads was $\approx 2 \mathrm{~mm}$. Each FEP sample holder was loaded with about 60 beads. The samples were all prepared on 8-FEB-93 and shipped in a $\mathrm{LN}_{2}$-cooled "dry shipper," which arrived at U. Va. on 10-FEB-93.

After the DNP test was completed, a visual inspection of the beads at $U$. Va. found that they all appeared to be glassy, although there was more surface cloudiness than experienced at ANL for a comparable age of bead. This may have been due to the fact that temperatures in a "dry shipper" may rise a few degrees above $77 \mathrm{~K}$ during shipment.

\subsection{DNP results}

The U. Va. polarized target apparatus operates at magnetic fields near $5 \mathrm{~T}$ and temperatures down to $1 \mathrm{~K}$. The following Table shows the results of the measurements.

\begin{tabular}{ccccc}
\hline \hline DTBN Concentration & Temperature & Relaxation & \multicolumn{2}{c}{ Polarization $(\%)$} \\
\cline { 5 - 5 }$\left(\right.$ spins $\left./ \mathrm{cm}^{3}\right)$ & $(\mathrm{K})$ & Time $(\mathrm{min})$ & without FM & with FM \\
\hline $4 \times 10^{19}$ & $\approx 1.0$ & - & $<1$ & $<1$ \\
$3 \times 10^{19}$ & $\approx 1.6$ & $<1$ & $\approx+1$ & $\approx+2$ \\
& $\approx 1.0$ & 8.9 & - & $\approx+3.5$ \\
$2 \times 10^{19}$ & $\approx 1.6$ & - & $\approx+2.0$ & - \\
& $\approx 1.0$ & 36 & $\approx+8.0$ & $+15,-19$ \\
\hline \hline
\end{tabular}

The entries marked "-" indicate that a reliable measurement was not made. The most important feature of these data is the indication that we did not manage to "bracket" the optimal doping level. The highest proton polarization of $-19 \%$ was reached in the lowest-concentration sample. More important, the polarization dependence on doping level is so steep over this range of concentration that it is 
impossible to estimate what polarization might be achieved at lower concentrations. Thus, beyond establishing that some degree of polarization is indeed possible, the outcome of this DNP test is rather frustrating.

Some other features of the data are worth noting. Not only is the concentration dependence steep, but the other dependences are, also. Both the proton relaxation time and the polarization show a strong dependence on the operating temperature, and the polarization shows a marked response to frequency modulation (FM) of the microwaves. (No attempt was made to optimize the FM parameters. The frequency of the FM was simply fixed at $1 \mathrm{kHz}$ and the amplitude was likewise fixed, and not well measured. The amplitude was thought to be a few tens of $\mathrm{MHz}$.)

Other operating conditions were as follows: The center NMR frequency was 207.5 $\mathrm{MHz}$, corresponding to a static magnetic field of $4.87 \mathrm{~T}$. The highest positive polarization of $+15 \%$ was achieved at a microwave frequency of $136.71 \mathrm{GHz}$; the highest negative of $-19 \%$, at $137.03 \mathrm{GHz}$.

\section{Conclusion}

The results of the glass-formation investigation are, so far, very encouraging. It now seems more likely that hydrocarbon glasses with hydrogen content close to $20 \mathrm{wt} \%$ are feasible.

The results of the "prototype" DNP test are ambiguous. It is not clear that "interesting" levels of polarization might be reached, using DTBN, nor is the possibility ruled out. Obviously, more tests would be needed. Unfortunately, the U. Va. apparatus had to be moved to SLAC for a scattering experiment immediately following the DNP test. Perhaps the opportunity for some further testing at $5 \mathrm{~T}$, at SLAC, might arise later on this year. There may also be a chance for testing at $2.5 \mathrm{~T}$, a.t LAMPF, or in a different apparatus, at $\mathrm{U}$. Va.

\section{References}

[1] D. A. Hill, The Prospects for Polarized Target Materials with Pure Carbon Background, Argonne Report ANL-HEP-TR-92-88.

[2] B. Wunderlich, J. Phys. Chem. 64 (1960) 1052.

[3] C. A. Angell et al., J. Phys. Chem. 82 (1978) 2622.

[4] V. I. Lozovoi et al., Nauchn. Tr., Gruz. Politekh. Inst. im. V. I. Lenina 11 (1980) 62 .

[5] T. Wakayama et al., J. Phys. Chem. 74 (1970) 3584. 

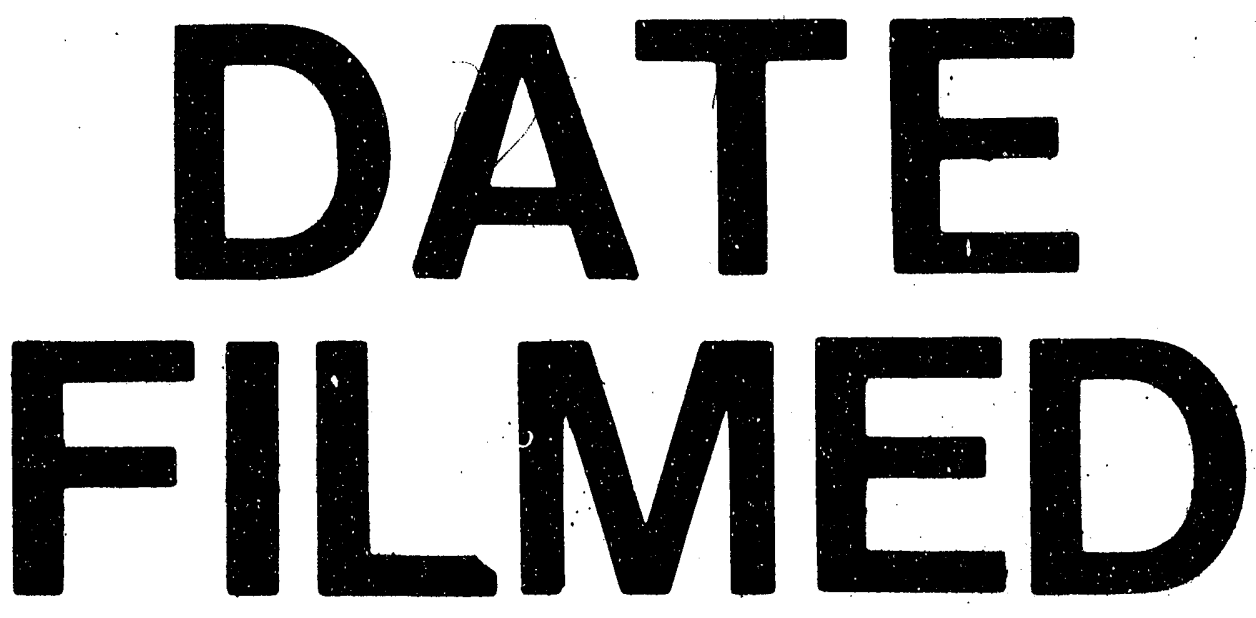

1

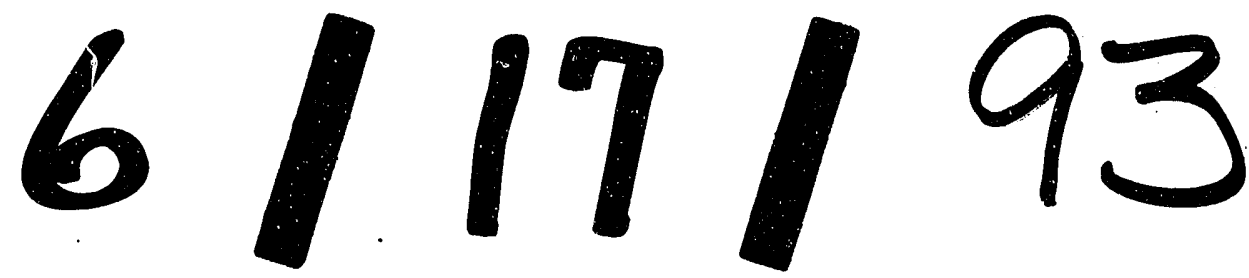


